\title{
Relações interculturais na vida universitária: experiências de mobilidade internacional de docentes e discentes
}

\author{
ADRIANA LEÔNIDAS DE OLIVEIRA \\ Universidade de Taubaté, Taubaté, SP, Brasil \\ MARIA ESTER DE FREITAS \\ Fundação Getúlio Vargas, São Paulo, SP, Brasi
}

RESUMO

O presente estudo teve como objetivo analisar experiências interculturais de alunos e professores universitários que realizaram programas de mobilidade acadêmica internacional, focalizando os desafios vivenciados, os aspectos facilitadores e os ganhos alcançados. Foram conduzidas 30 entrevistas e o material obtido foi analisado qualitativamente com o auxílio do software Ethnograph. Resultados apontam que os maiores desafios concernem ao processo de adaptação sociocultural, sendo uma das principais dificuldades a barreira do idioma. Entre os elementos facilitadores destacam-se a relação com outros intercambistas e o apoio dos professores. A experiência de mobilidade revela-se como favorecedora da construção de um importante capital simbólico, contribuindo para o desenvolvimento de competências pessoais, interculturais, profissionais e acadêmicas. Destaca-se o papel da universidade nesse processo por meio de ações de apoio e orientação aos envolvidos.

\section{PALAVRAS-CHAVE}

internacionalização da educação superior; mobilidade acadêmica internacional; experiência intercultural. 


\section{INTERCULTURAL RELATIONS IN UNIVERSITY LIFE: EXPERIENCES OF INTERNATIONAL MOBILITY OF PROFESSORS AND STUDENTS}

\section{ABSTRACT}

This study aimed at analyzing intercultural experiences of students and university professors who conducted international academic mobility programs, focusing on the challenges experienced, the fostering aspects and the gains achieved. Thirty interviews were conducted and the material obtained was qualitatively analyzed with the aid of the Ethnograph software. Results show that the biggest challenges relate to the cultural adaptation process, being the language barrier one of the main difficulties. The fostering aspects include the relationship with other exchange students and the support of professors. The mobility experience reveals itself to be a facilitator of the construction of an important symbolic capital, contributing to the development of personal, academic, professional and intercultural skills. The role of the University in this process stands out in actions of support and guidance to those involved.

\section{KEYWORDS}

internationalization of higher education; international academic mobility; intercultural experience.

\section{RELACIONES INTERCULTURALES EN LA VIDA UNIVERSITARIA: EXPERIENCIAS DE MOVILIDAD INTERNACIONAL DE DOCENTES Y ESTUDIANTES}

\section{RESUMEN}

El presente estudio tuvo como objetivo analizar experiencias interculturales de estudiantes y profesores universitarios que realizaron programas de movilidad académica internacional enfocando los desafíos vividos, los aspectos facilitadores y los logros alcanzados. Fueron encaminadas treinta entrevistas y el material obtenido fue analizado cualitativamente con la ayuda del software Ethnograph. Los resultados indicaron que los mayores desafíos se relacionan con el proceso de adaptación sociocultural teniendo como principal dificultad la barrera del idioma. Entre los elementos facilitadores se destaca la relación con otros estudiantes de intercambio y el apoyo de los profesores. La experiencia de movilidad se revela como favorecedora de la construcción de un importante capital simbólico, contribuyendo para el desarrollo de competencias personales, interculturales, profesionales y académicas. En ese proceso se destaca el papel de la universidad por medio de acciones hacia los involucrados.

\section{PALABRAS CLAVE}

internalización de la educación superior; movilidad académica internacional; experiencia intercultural. 


\section{INTRODUÇÃO}

A universidade é um lugar de encontro e de troca dos saberes. Conhecimentos são produzidos e abrigados, e passam por uma reflexão crítica na universidade. É o espaço no qual se busca autonomia, o local em que se constroem, se conservam e se desenvolvem os valores importantes para o ser humano e para a sociedade. Sendo um espaço de culturas, a interculturalidade é uma condição inerente à sua existência, favorecendo o convívio e a integração de diversidades.

A orientação intercultural, vista como um modelo de abordagem da diversidade cultural (Abdallah-Pretceille, 2004), indica a necessidade de integrar grupos minoritários, mediar a comunicação entre diferentes grupos e promover a convivência comum (De Carlo, 1998). Conforme De Carlo (1998), interculturalidade prevê atribuir ao prefixo "inter" sua plena significação, no sentido de interação, troca, eliminação das barreiras e reciprocidade. Ainda, Abdallah-Pretceille (2004) enfatiza seu cunho educativo, visto que favorece a compreensão dos problemas sociais e educativos relacionados à diversidade cultural. $\mathrm{O}$ intercultural corresponde a uma forma de ver o outro e um exercício de alteridade.

Falar de interculturalidade no contexto universitário remete-nos à questão do processo de internacionalização do Ensino Superior, que tem ampliado os encontros e as convivências de diferentes realidades culturais no espaço acadêmico. A internacionalização pode ser vista como um esforço direcionado para tornar a educação superior mais ajustável às exigências e aos desafios relacionados à globalização, cuja influência pode ser vista nos campos econômico, político, cultural e também educacional.

Como um processo espacial e temporal, a globalização tem cada vez mais desenhado um mundo de interconexão e de integração de culturas e comunidades. É uma força poderosa que impulsiona a mudança de práticas e de formas de se conceber o mundo, assim como o lugar do homem no universo. Intensos são os desafios para as Instituições de Educação Superior (IES) advindos da globalização, as quais têm questionado sua missão e responsabilidade no sentido de preparar alunos para se tornarem cidadãos globais e profissionais capazes de atender a complexidade da sociedade atual.

O movimento de internacionalização da educação superior tem se acelerado principalmente a partir da década de 1990, e hoje é um processo consolidado em muitas universidades em todo o mundo; contudo, ele tem se manifestado de forma desequilibrada (Lima; Contel, 2011). Nos países do centro da economia-mundo é um processo bastante ativo, com implantação de políticas voltadas para atração e acolhimento de acadêmicos, oferta de serviços educacionais no exterior e exportação de programas e instalação de campi (Lima; Maranhão, 2009). Universidades buscam diversificar a oferta de serviços e atrair estudantes como forma de ampliar a margem de autofinanciamento (Lima et al., 2009). Os países periféricos, por outro lado, possuem uma capacidade limitada para ações dessa natureza (Lima; Maranhão, 2009), sendo os principais consumidores dos serviços educacionais ofertados pelos países centrais. Números da UNESCO (2008) evidenciam que o crescimento da mobilidade internacional ocorre particularmente dos 
países periféricos e semiperiféricos para os países centrais, a exemplo dos Estados Unidos, que acolhem $26 \%$ da população estudantil internacional e enviam apenas 2\% (Lima et al., 2009). É nesse cenário que o protagonismo do mercado confere à internacionalização uma lógica mercantil, cuja problematização merece reflexão crítica (Lima et al., 2009).

Segundo Knight (2014), a internacionalização da educação superior é um processo que integra uma dimensão internacional e intercultural ao ensino, à pesquisa e aos serviços de uma instituição. Assim, corresponde a um conjunto de esforços para capacitar o Ensino Superior a responder aos desafios da globalização da sociedade, da economia e do mercado de trabalho (Urban; Palmer, 2014; Wende, 2011; Jackson, 2008). O atual cenário dessa internacionalização nos mostra múltiplas possibilidades de se desenvolver cooperação entre universidades, por meio de colaboração científica, tecnológica ou cultural, das equipes conjuntas de pesquisa e publicações, dos diplomas compartilhados e da mobilidade de docentes e discentes na graduação e pós-graduação. Entretanto, embora compreenda um conjunto amplo de políticas, estratégias e ações, os programas de mobilidade acadêmica fazem parte das principais modalidades de internacionalização.

Apesar de não ser um fenômeno novo, foi no início deste século que a mobilidade acadêmica passou a se caracterizar como uma categoria de estudo relevante, tendo em vista a intensidade com que tem se manifestado (UNESCO, 1998, 2009). Os números evidenciam que, depois de 1999, houve um aumento de $53 \%$ no número de alunos internacionais em circulação, revelando um crescimento médio de 5,5\% ao ano (UNESCO, 2009). Em 2010, o número estimado de alunos estrangeiros no mundo foi de 4,1 milhões (OCDE, 2012), e uma expansão exponencial é prevista para os próximos anos, como resultado do aumento das expectativas dos alunos, dos benefícios trazidos para as IES envolvidas, da melhora da qualidade do capital humano e da competitividade que a mobilidade pode proporcionar, especialmente nos países de economia emergente (Vázquez et al., 2014). A UNESCO estima que o número de alunos que estará matriculado na educação superior fora de seu país de origem chegará a 8 milhões, em 2025 (Jackson, 2008).

Apesar da mobilidade acadêmica internacional não assumir o mesmo sentido e importância em todas as regiões do mundo (Knight, 2014; Lima; Contel, 2011), ela tem ganhado centralidade nas diretrizes educacionais dos países latino-americanos (Castro; Castro Neto, 2012), inclusive no Brasil este é um fenômeno que tem crescido em números e em relevância, em razão das mudanças na direção de implementação de políticas públicas relacionadas à educação superior (Lima; Contel, 2011).

A força do fenômeno da mobilidade acadêmica internacional na atualidade nos coloca diante de uma realidade desafiadora e complexa. Se por um lado a experiência de estudar em outro país abre uma série de oportunidades de aprendizagem para o aluno internacional, por outro, lhe traz uma série de desafios, pois demanda adaptação do indivíduo a fatores acadêmicos, socioculturais e psicológicos. 
O presente artigo busca contribuir para a compreensão do fenômeno da mobilidade acadêmica no Brasil, onde os estudos ainda são escassos. O nosso objetivo foi o de analisar as experiências interculturais de alunos e professores universitários que realizaram programas de mobilidade acadêmica internacional, focalizando os desafios vivenciados, os aspectos facilitadores e os ganhos alcançados. A partir de uma pesquisa qualitativa buscamos compreender a perspectiva tanto de estudantes e professores brasileiros, que realizaram estudos no exterior como parte da sua formação acadêmica, como a de alunos estrangeiros, que vieram ao Brasil com essa finalidade. Neste trabalho tomamos como base teórica a noção de capital simbólico trazida da obra de Bourdieu (1982, 2003, 2006), uma vez que a mobilidade é compreendida como um capital simbólico no mundo contemporâneo (Freitas, 2005, 2009; Allemand, 2004). Além disso, estudos da área da educação internacional que abordam questões interculturais também foram utilizados para interpretação do material obtido.

Visando aos objetivos propostos, o artigo está estruturado em três partes: uma breve revisão de literatura para contextualização teórica da temática, os procedimentos metodológicos adotados e a apresentação e interpretação dos dados coletados em campo, o que nos conduz às considerações finais.

\section{O MUNDO UNIVERSITÁRIO, A MOBILIDADE INTERNACIONAL E A INTERCULTURALIDADE}

É consenso na literatura que a internacionalização é uma marca das relações entre universidades, não sendo, portanto, um fenômeno recente, embora tenha se intensificado no panorama mundial a partir da década de $1990 \mathrm{com}$ a aceleração do processo de globalização (Morosini, 2006; Stallivieri, 2004; Lima; Contel, 2011; Castro; Castro Neto, 2012). No Brasil, as primeiras marcas de internacionalização fazem-se presentes desde a criação das primeiras universidades brasileiras, na década de 1930, com a vinda de professores visitantes da Europa, com o objetivo de se consolidar o projeto acadêmico das instituições emergentes (Lima; Contel, 2011).

O processo de internacionalização do Ensino Superior passou por mudanças e evoluções, e na atualidade os programas de mobilidade são os que mais têm se fortalecido, destacando-se como um dos campos mais férteis e visíveis para a cooperação acadêmica internacional (Araújo; Silva, 2015; Vázquez et al., 2014; Knight, 2014; Lauermann, 2012; De Wit, 2010; Altbach, 2008). No Brasil, apesar das dificuldades para implantação contínua de políticas públicas de internacionalização de efeitos duráveis, os programas de mobilidade acadêmica também constituem realidade em expansão (Guimarães et al., 2013) e têm possibilitado a abertura para o encontro e a convivência de diferentes culturas. Como exemplo, temos o Programa Ciência sem Fronteiras, criado em 2011 pelo governo federal brasileiro, cujo objetivo é promover consolidação, expansão e internacionalização da ciência e da tecnologia, da inovação e da competitividade brasileira por meio do intercâmbio e da mobilidade internacional (Ciência Sem Fronteiras, 2016). 
A convivência intercultural assume uma posição cada vez mais importante na vida social e organizacional (Freitas, 2009). Na vida universitária tal relevância é inquestionável, porém o sucesso dessas experiências interculturais demanda de seus atores sensibilidade às diferentes particularidades culturais, clarificando questões relativas ao poder, às estruturas institucionais e às práticas culturais, de forma a capitalizar a diversidade cultural para o sucesso da experiência e a construção do senso de comunidade (Lillyman; Bennett, 2014; Ujitani; Volet, 2008).

Tomando como base a noção de capital simbólico (Bourdieu, 1982, 2003, 2006), propomos tratar a mobilidade como um bem ou um valor atual; ou, mais especificamente, como um capital simbólico no mundo contemporâneo - o capital mobilidade (Freitas, 2005; 2008; 2009; Allemand, 2004; Murphy-Lejeune, 2007, 2003, 2002).

Murphy-Lejeune (2002; 2007) discute a construção do capital mobilidade no contexto universitário e o define como um componente do capital humano que expressa tanto o ponto de partida como a riqueza acumulada ao longo da experiência de mobilidade, que compreende as histórias familiar e pessoal, as competências linguísticas, as experiências de mobilidade e os traços de personalidade do sujeito, como flexibilidade, abertura para o novo e para as diferenças culturais. O capital de mobilidade expressa um alargamento do sentimento identitário, do crescimento pessoal e da maturidade intelectual, sendo essas conquistas transferíveis a outras situações de vida que ultrapassam o aspecto universitário, pois é um "saber ser" que engloba um "saber fazer" aos demais saberes (Bourdieu, 2006; 2003; 1982; Freitas, 2005).

Podemos compreender que o capital de mobilidade é multifacetado, uma vez que antes da vivência da mobilidade, o estudante pode apresentar diferentes competências, as quais serão transformadas durante a experiência em si. Assim, esse capital é modificado à medida que o indivíduo desenvolve estratégias para se adaptar e, no processo, adquire uma diversidade de habilidades e conhecimentos (Murphy-Lejeune, 2007, 2003, 2002).

\section{MÉTODO DE PESQUISA}

Optamos pela realização de uma pesquisa exploratória, a partir de uma abordagem qualitativa. Técnicas qualitativas de coleta e análise de dados foram usadas, a fim de se alcançar uma visão global e integradora do tema proposto.

Realizaram-se entrevistas semiestruturadas junto a estudantes brasileiros e estrangeiros de graduação e pós-graduação, assim como com professores universitários brasileiros, os quais optaram pela mobilidade internacional como parte da sua formação acadêmica. A entrevista semiestruturada apresenta certo grau de estruturação, uma vez que o pesquisador se guia por uma relação ou um roteiro de perguntas, a fim de explorar aspectos significativos da fala do entrevistado (Oliveira, 2007).

As características do grupo amostral, composto por 30 participantes, podem ser visualizadas no Quadro 1. 
Quadro 1-Caracterização dos participantes.

\begin{tabular}{|c|c|c|c|c|}
\hline & & $\begin{array}{c}\text { Alunos } \\
\text { brasileiros }\end{array}$ & $\begin{array}{c}\text { Alunos } \\
\text { estrangeiros }\end{array}$ & $\begin{array}{c}\text { Professores } \\
\text { brasileiros }\end{array}$ \\
\hline \multicolumn{2}{|r|}{ Total } & 12 & 10 & 8 \\
\hline \multirow{2}{*}{ Sexo } & Feminino & 8 & 4 & 4 \\
\hline & Masculino & 4 & 6 & 4 \\
\hline \multirow{3}{*}{$\begin{array}{l}\text { Área de estudo/ } \\
\text { formação }\end{array}$} & Humanas & 6 & 10 & 6 \\
\hline & Biociências & 3 & - & 2 \\
\hline & Exatas & 3 & - & - \\
\hline \multirow{2}{*}{$\begin{array}{l}\text { Universidade } \\
\text { de origem }\end{array}$} & Pública & 8 & 6 & 3 \\
\hline & Particular & 4 & 4 & 5 \\
\hline \multirow{2}{*}{$\begin{array}{l}\text { Universidade } \\
\text { de destino }\end{array}$} & Pública & 9 & 1 & 6 \\
\hline & Particular & 3 & 9 & 2 \\
\hline \multirow{4}{*}{ País de origem } & Brasil & 12 & - & 8 \\
\hline & $\begin{array}{l}\text { Outros países da } \\
\text { América do Sul }\end{array}$ & - & 1 & - \\
\hline & Países da Europa & - & 7 & - \\
\hline & Países da África & - & 2 & - \\
\hline \multirow{5}{*}{ País de destino } & Brasil & - & 10 & - \\
\hline & $\begin{array}{l}\text { Outros países da } \\
\text { América do Sul }\end{array}$ & 1 & - & - \\
\hline & $\begin{array}{c}\text { Países da América } \\
\text { do Norte }\end{array}$ & - & - & 4 \\
\hline & Países da Europa & 10 & - & 5 \\
\hline & Países da Ásia & 1 & - & - \\
\hline \multirow{5}{*}{$\begin{array}{l}\text { Finalidade da } \\
\text { mobilidade }\end{array}$} & Graduação sanduíche & 10 & 3 & - \\
\hline & Mestrado & 1 & 5 & 1 \\
\hline & Doutorado & 1 & 2 & - \\
\hline & Doutorado Sanduíche & - & - & 5 \\
\hline & Pós-doutorado & - & - & 4 \\
\hline \multirow{2}{*}{$\begin{array}{l}\text { Já havia } \\
\text { viajado para o } \\
\text { exterior antes }\end{array}$} & $\operatorname{Sim}$ & 8 & 10 & 8 \\
\hline & Não & 4 & - & - \\
\hline \multirow{2}{*}{$\begin{array}{l}\text { Já dominava } \\
\text { o idioma }\end{array}$} & Sim & 7 & 3 & 4 \\
\hline & Não & 5 & 7 & 4 \\
\hline
\end{tabular}

Fonte: Dados das entrevistas. 
Para o tratamento dos dados utilizamos técnicas de análise de conteúdo, e entre as diversas formas que esta pode assumir (Bardin, 1995), optamos pela análise por categorias temáticas, definidas a posteriori e induzidas pelo instrumento de coleta usado. O software Ethnograph w5.0 (Seidel, 1998) foi utilizado como instrumento auxiliar no processo de codificação dos dados. Trata-se de um software desenvolvido para contribuir no processo de manejo de dados qualitativos, oferecendo recursos para que os exercícios analíticos de análise do pesquisador sejam registrados em compartimentos adequados, para que possam ser consultados prontamente ao longo de todo o trabalho. Assim, ressalta-se que o software Ethnograph não realiza o trabalho de codificação para o pesquisador, mas o auxilia nesse processo (Seidel; Clark, 1984) à medida que suas ferramentas possibilitam organizar os dados, facilitando a realização da análise de conteúdo.

\section{RESULTADOS}

Foram construídas três grandes categorias, cujos conteúdos são apresentados nos três grupos analisados, permitindo uma discussão comparativa entre eles:

$1^{\mathrm{a}}$ - Desafios vivenciados;

$2^{\mathrm{a}}$ - Elementos facilitadores; e

$3^{\mathrm{a}}-$ Ganhos alcançados.

\section{DESAFIOS VIVENCIADOS}

$\mathrm{Na}$ Figura 1, são apresentados os principais desafios identificados nas experiências dos entrevistados.

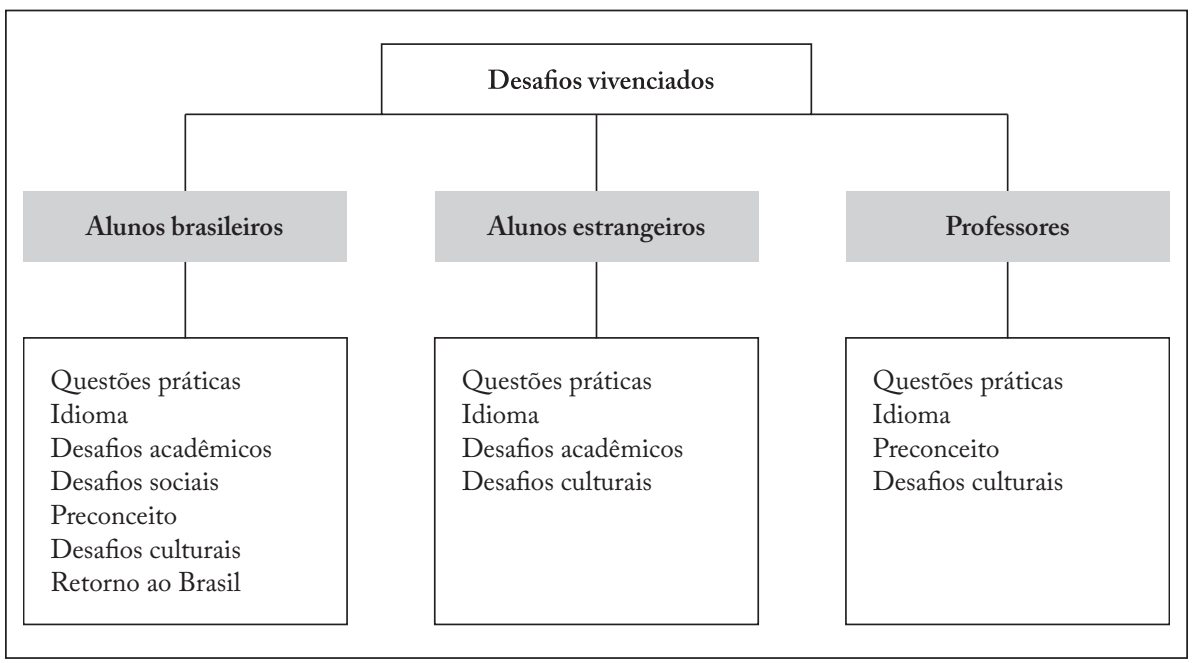

Figura 1-Categoria 1: Desafios vivenciados.

Fonte: Dados das entrevistas. 
Ao analisarmos os desafios vivenciados na experiência de mobilidade internacional constatamos que os principais referem-se ao processo de adaptação sociocultural, os quais se fazem presentes dentro e fora do contexto universitário. Embora, de forma geral, os desafios sejam similares para alunos e professores brasileiros no exterior e alunos estrangeiros no Brasil, como pode se observar na Figura 1, constatamos que a forma como tais desafios são vividos é diferente.

Especialmente no início da experiência da mobilidade os sujeitos se confrontam com dificuldades advindas de questões práticas, tais como documentação, acomodação e abertura de conta bancária. Tais dificuldades foram evidenciadas nos três grupos pesquisados.

Outro importante desafio apontado por todos os participantes dos três grupos é o idioma. Para alunos e professores brasileiros no exterior, a língua é percebida como um obstáculo dentro e fora da universidade, gerando principalmente dificuldades acadêmicas, e também nas atividades do dia a dia.

Às vezes eu pronunciava alguma palavra errada ou não sabia o que significava e atrapalhava o conteúdo da frase inteira. Isso, durante uma apresentação, era motivo de risada perante os alunos espanhóis. $\mathrm{Na}$ vida do dia a dia, tinha dificuldade em acompanhar o ritmo como as pessoas falavam. (brasileira, 20 anos, graduanda na Espanha)

Interessante observar que, embora o idioma também apareça na fala dos alunos estrangeiros no Brasil como um importante desafio a ser vencido, as dificuldades decorrentes da pouca proficiência linguística parecem ocorrer mais nas atividades acadêmicas, visto que no dia a dia, fora da universidade, encontram, na maioria das vezes, paciência e receptividade do povo brasileiro para lidar com os entraves da língua. Tais atitudes dos brasileiros despontam, portanto, segundo os entrevistados, como um elemento facilitador, que será apresentado na próxima categoria.

It's a challenge, the Portuguese, but I don't think it's a barrier because I try and people here are really helpful. If I don't succeed to say what I want in Portuguese, I can ask someone on the street if they speak English and I can get help. Brazilian people take time for you. (francesa, 23 anos, mestranda no Brasil)

Observou-se que os desafios acadêmicos foram apontados apenas pelos alunos brasileiros e estrangeiros, não tendo sido uma dificuldade dos professores brasileiros no exterior, muito provavelmente pelo nível de formação já consolidada.

Tais desafios dizem respeito ao estilo de aula e metodologias utilizadas (por exemplo, aulas mais expositivas, aulas de discussão, atividades em grupo e ausência ou realização de atividades práticas) e aos métodos de avaliação e níveis de exigência, os quais eram diferentes da universidade de origem. Além disso, 
conforme apontado anteriormente, o idioma se desdobra também em um desafio acadêmico, por dificultar a compreensão das aulas e expressão do aluno nas avaliações.

Here professors give more interactive classes and group work. In Germany we don't have this kind of system. It is a challenge to me to adapt. (alemão, 23 anos, graduando no Brasil)

Outro fator percebido como desafio é a relação professor-aluno, nesse caso, na perspectiva dos alunos brasileiros no exterior. Eles, na sua grande maioria, afirmam que há um grande distanciamento afetivo por parte do professor, sendo muito diferente do tipo de relação que se constrói com os mestres no Brasil.

Os desafios sociais, apontados por alunos brasileiros, dizem respeito às dificuldades nos relacionamentos com outros estudantes dentro e fora do contexto universitário e na construção de amizades e redes sociais. A principal dificuldade foi a falta de abertura para os relacionamentos por parte dos alunos locais e, em alguns casos, a postura muito competitiva destes, aspectos que dificultavam a formação de amizades ou resultavam em isolamento social.

Meus colegas de sala eram muito fechados e eu não fiz praticamente nenhuma amizade que não fosse com os brasileiros. Achei estranha essa falta de interesse dos estudantes locais com os alunos internacionais [...] Eles não ligam, não se importam e não querem nem saber de você. (brasileira, 23 anos, graduanda na Inglaterra)

O preconceito foi um desafio explicitamente apontado no relato da maioria dos alunos brasileiros que estudaram no exterior, os quais indicaram experiências nesse sentido tanto dentro quanto fora da universidade.

Eu tive uma professora preconceituosa, que claramente discriminava europeu, latino e africano. Uma atividade prática em que fiz dupla com um estudante local. Ele tirou vinte, a nota máxima, e eu tirei 16 . O relatório foi o mesmo, a única coisa que mudava era o sobrenome. (brasileira, 22 anos, graduanda no Reino Unido)

No relato de professores brasileiros também foram apontadas situações de preconceito:

Senti preconceito mais de uma vez, dentro e fora da universidade. Acho que as situações mais evidentes foram em seminários. Você não ser um europeu, isso de saída, te localizava numa posição simbólica menor. Suas palavras não tinham o mesmo peso que tinha a palavra de outros, por mais que, em termos de conhecimento, você estivesse igualado. (professor brasileiro, fez doutorado sanduíche e pós-doutorado na França)

Os desafios culturais foram apontados pelos participantes dos três grupos. Lidar com as diferenças culturais no dia a dia, em termos de costumes e hábitos, 
assim como com as diferenças nos traços culturais do povo, em comparação com a cultura de seu país de origem, foi apontado como desafio dentro e fora da universidade.

A assertividade às vezes me chocava. Os europeus são bem mais secos. (brasileiro, 20 anos, graduando na França)

Para os alunos estrangeiros no Brasil, os principais desafios culturais foram relacionados a características do povo brasileiro, como lidar com a sua informalidade:

$\mathrm{Na}$ primeira aula a professora veio pra abraçar os alunos. Fiquei muito surpreso! Nunca vi isso na França! Também as formas de interagir dos alunos e do professor, acho que é bastante informal. (francês, 23 anos, mestrando no Brasil)

O último desafio analisado foi apontado por alguns alunos brasileiros e diz respeito às vivências e aos sentimentos intensos de medos, angústias, preocupações e aflições relacionados ao retorno ao Brasil:

Eu estava muito preocupada em como seria a minha volta. Se me adaptaria à nova sala, se faria amigos lá ou se não teria amigos como não tinha em Nebrija; se minha família já tinha me esquecido; se meus amigos já tinham me esquecido; se eu iria arrumar emprego; se eu iria emagrecer. (brasileira, 20 anos, graduanda na Espanha)

Eu acho que tem que ter uma preparação psicológica, tanto pra ir e principalmente para voltar. Não é fácil voltar. Você tem que se readaptar quando volta [...] Tudo muda, nada é igual... e você também não é. (brasileira, 21 anos, graduanda em Portugal)

\section{ELEMENTOS FACILITADORES}

Embora a experiência da mobilidade acadêmica internacional seja permeada por uma série de desafios, também podemos identificar elementos facilitadores, que contribuem para o enfrentamento das dificuldades. Tais elementos, cujos conteúdos compõem a Categoria 2, são apresentados na Figura 2.

Ao analisarmos os elementos facilitadores da experiência intercultural na universidade, um dos aspectos fortemente enfatizado pelos estudantes entrevistados diz respeito ao aspecto social, ou seja, as relações formadas dentro do contexto universitário. Percebe-se que alunos em mobilidade tendem a formar mais redes de relacionamentos com outros alunos na mesma condição, por viverem experiências semelhantes, do que com estudantes locais.

No grupo dos professores entrevistados tal aspecto também foi observado. A relação com colegas brasileiros, pessoas também em mobilidade acadêmica para fins de doutorado e pós-doutorado, foi apontada como aspecto facilitador, embora com muito menos ênfase nesse grupo de entrevistados do que entre os 
alunos. Para os professores, outros elementos facilitadores foram mais importantes na vivência da experiência intercultural, com destaque para o apoio do professor orientador.

Acho que o que ajuda é que sempre fico com os outros intercambistas. Quando você está sozinho tende a ajeitar-se com pessoas que estão sozinhas também. (espanhola, 26 anos, mestranda no Brasil)

O apoio dos professores foi também um elemento facilitador da vivência intercultural dentro do contexto universitário ressaltado pelos entrevistados dos três grupos. Os alunos brasileiros enfatizam que a relação professor-aluno é muito diferente da relação aluno-professor no Brasil, no sentido de ser mais formal, mas, por outro lado, muito acessível do ponto de vista pedagógico.

Foi consenso entre os alunos estrangeiros no Brasil que o apoio do professor é elemento-chave na facilitação da aprendizagem. Destacam em suas falas o relacionamento mais caloroso e afetuoso, que faz com que o aluno sinta-se bem acolhido e à vontade.

Os professores todos são excelentes! Em qualquer dificuldade eles sempre gostam de apoiar. Pra isso eu dou nota dez! O professor é uma peça-chave facilitadora. (moçambicano, 45 anos, doutorando no Brasil)

$\mathrm{Na}$ experiência de mobilidade do grupo de professores entrevistados, o apoio do professor-orientador também desponta como elemento facilitador importante.

\begin{tabular}{|c|c|c|}
\hline & Elementos facilitadores & \\
\hline Alunos brasileiros & Alunos estrangeiros & Professores \\
\hline $\begin{array}{l}\text { - relação com alunos } \\
\text { brasileiros } \\
\text { - relação com outros } \\
\text { intercambistas } \\
\text { - apoio dos professores } \\
\text { - apoio da universidade } \\
\text { - domínio do idioma } \\
\text { - características do povo } \\
\text { brasileiro } \\
\text { - bagagem cultural } \\
\text { - características pessoais } \\
\text { - tecnologia }\end{array}$ & $\begin{array}{l}\text { - relação com outros } \\
\text { intercambistas } \\
\text { - apoio dos professores } \\
\text { - características do povo } \\
\text { brasileiro } \\
\text { - ausência de preconceito } \\
\text { - bagagem cultural } \\
\text { - características pessoais } \\
\text { - tecnologia }\end{array}$ & $\begin{array}{l}\text { - relação com colegas } \\
\text { brasileiros } \\
\text { - apoio do professor/ } \\
\text { orientador } \\
\text { - domínio do idioma } \\
\text { - bagagem cultural } \\
\text { - características do povo } \\
\text { brasileiro } \\
\text { - características pessoais } \\
\text { - tecnologia }\end{array}$ \\
\hline
\end{tabular}

Figura 2 - Categoria 2: Elementos facilitadores.

Fonte: Dados das entrevistas. 
O suporte da universidade foi um elemento indicado apenas pelos alunos brasileiros em mobilidade no exterior, que relatam diferentes aspectos desse apoio:

- existência de um departamento ou diretoria internacional que centralizava as informações e orientações aos intercambistas; contato anterior à viagem para informações e orientações iniciais;

- evento de recepção;

- alojamento na universidade;

- apoio à busca de moradia;

- existência de um professor tutor para acompanhar o aluno;

- canais contínuos de comunicação com os alunos intercambistas (e-mail, mural, informativos);

- eventos de integração; e

- convênios da universidade com instituições de diferente natureza.

A organização e o acolhimento foram enfatizados pelos alunos:

Eles preparam os alunos com informações antes da viagem. Quando chega, você tem um professor tutor específico pra te receber e acompanhar. (brasileira, 21 anos, graduanda no Chile)

A universidade te apoia muito. Essas ações da universidade facilitam muito. (brasileira, 22 anos, graduanda no Reino Unido)

As características do povo brasileiro foram aspectos ressaltados como facilitador nos três grupos de entrevistados, os quais destacam a flexibilidade e a sociabilidade do povo:

Tem a nossa sociabilidade, a gente é um povo muito mais aberto, a gente conversa com as pessoas... Isso facilita bastante. (brasileiro, 30 anos, doutorando na França)

Os professores brasileiros, apesar de também apontarem a característica de sociabilidade do povo como positiva para a vivência intercultural, chamam a atenção para o fato de que essa mesma característica pode ser negativa se as diferenças culturais não forem respeitadas:

É fato que brasileiro consegue se aproximar mais facilmente das pessoas, mas isso tem uma medida. Muitas vezes a gente passa por mal-educado com nossa espontaneidade. (professor brasileiro, fez doutorado sanduíche e pós-doutorado na França)

Os alunos estrangeiros no Brasil também apontam a característica de sociabilidade do povo como favorecedora para inserção e adaptação no Brasil. Aliado a isso, enfatizam a abertura do povo brasileiro e ausência de preconceito com relação ao estrangeiro:

Brazilian people are open mind and helpful. There is no prejudice anyway. The adaptation becomes much easier. (alemão, 23 anos, graduando no Brasil). 
As pessoas são acolhedoras, têm curiosidade. Brasileiro gosta muito de estrangeiro. (francesa, 25 anos, mestranda no Brasil)

Se por um lado a língua é um grande obstáculo, quando não dominada, o controle do idioma favorece muito a experiência, não apenas dentro como fora da universidade, sendo apontado como elemento facilitador por alunos e professores brasileiros:

Como eu já falava o francês, eu diria que foi fácil a adaptação à cidade, ao país. $\mathrm{Na}$ universidade não tive dificuldade com a língua. (brasileiro, 20 anos, graduando na França)

A bagagem cultural foi um elemento apontado pelos entrevistados nos três grupos. Alunos e professores brasileiros, assim como estrangeiros, enfatizam que experiências anteriores de viagens internacionais e o conhecimento da cultura local e de outras culturas foram muito importantes nessa nova experiência.

Sempre viajei muito com minha família, morei em lugares diferentes. Essa bagagem foi importante pra mim. Você aprende a ser mais tolerante para as diferenças. (brasileiro, 30 anos, doutorando na França).

My previous experiences in different countries helped a lot. I think it was easy to me. (dinamarquês, 24 anos, mestrando no Brasil).

Características pessoais como otimismo, determinação, perseverança, paciência e sociabilidade também foram apontadas pelos participantes dos três grupos como aspectos facilitadores da experiência intercultural, bem como o uso da tecnologia para mediar contatos pessoais.

Apesar da saudade e das dificuldades, sempre mantive meu pensamento positivo e determinação. (brasileira, 25 anos, mestranda na França)

Havia dias que eu chorava muito. Senti muita saudade da minha família, do clima, do pão de queijo, do brigadeiro, dos sucos, da minha mãe fazer comida pra mim... Sempre conversávamos por Skype. Como seria se não tivesse o Skype? (brasileira, 20 anos, graduanda na Espanha)

\section{GANHOS ALCANÇADOS}

Tendo vivido experiências permeadas por diferentes desafios, os quais foram mediados por aspectos facilitadores, os ganhos alcançados são evidenciados, que remetem às competências desenvolvidas ao longo da experiência de mobilidade, similares para os três grupos: competências pessoais, interculturais, acadêmicas e profissionais. Observa-se, entretanto, que a importância de tais competências varia em cada grupo, refletindo as diferentes motivações e objetivos buscados, assim como o estágio de desenvolvimento vivido. 
Alunos brasileiros e estrangeiros apontam com maior ênfase que a experiência de mobilidade permitiu o desenvolvimento de competências pessoais. Tais competências dizem respeito:

- ao autoconhecimento;

- à ampliação de horizontes;

- ao desenvolvimento da autoconfiança em razão da descoberta da capacidade de superação de dificuldades; e

- ao desenvolvimento da autonomia, independência, responsabilidade e maturidade.

O aprimoramento de competências pessoais foi enfatizado por apenas um professor, uma vez que houve nesse grupo uma ênfase muito maior nos ganhos acadêmicos e profissionais.

Eu diria que é mais ou menos como as dores do parto. Difícil no começo, mas depois quando vai, é importante e recompensador. Você sai fortalecido pessoalmente. (professor brasileiro, fez doutorado sanduíche e pós-doutorado na França).

O desenvolvimento de competências interculturais também foi um ganho apontado com maior ênfase pelos alunos brasileiros e estrangeiros, as quais englobam aspectos ligados ao conhecimento de uma nova cultura (costumes, fatores históricos e sociopolíticos); habilidades e atitudes (aprendizado da língua estrangeira, flexibilidade na interação com as pessoas, ajustamento de comportamento e gestos, não julgamento das diferenças e saber como enfrentar e lidar com as diferenças) e sensibilidade (aprender a importância da diversidade, respeitar o diferente e compreender o que ajuda ou prejudica a interculturalidade).

Você aprende a olhar o outro e ter humildade pra saber como se comportar. (francês, 23 anos, mestrando no Brasil)

Os ganhos acadêmicos, traduzidos em competências acadêmicas desenvolvidas, foram pouco mencionados pelos alunos brasileiros e estrangeiros. Apenas uma aluna mencionou conteúdos estudados, que trouxeram enriquecimento acadêmico; outros poucos alunos mencionaram o aprimoramento da escrita científica acadêmica e da forma de estudar. Alguns alunos brasileiros até enfatizaram que os ganhos pessoais, interculturais e profissionais são maiores do que os acadêmicos propriamente ditos.

O pouco impacto da mobilidade internacional no desenvolvimento de competências acadêmicas também é apontado por alunos estrangeiros, que enfatizam os ganhos interculturais e profissionais da experiência:

The principal learnings are not the contents of the course. When you have an international experience you are focused in other things: learning another language and another culture. It is more importante for my personal and professional life. (dinamarquês, 24 anos, mestrando no Brasil) 
Ao contrário dos alunos brasileiros e estrangeiros, os professores dão grande ênfase ao desenvolvimento de competências acadêmicas. Essas aparecem muito ligadas às competências profissionais, por atuarem na área da docência e da pesquisa.

Eu passei a ter a possibilidade do intercâmbio de conhecimento e da parceria. $\mathrm{Eu}$ acho que eu mudei completamente a minha forma de ver a pesquisa e elaborar os projetos. (professor brasileiro, fez doutorado sanduíche e pós-doutorado nos Estados Unidos)

As competências profissionais apontadas pelos alunos brasileiros e estrangeiros, por outro lado, aparecem muito ligadas às competências interculturais desenvolvidas:

Ser versátil e capaz de trabalhar com pessoas dos mais diversos backgrounds, culturas e visões de mundo, é fundamental para o profissional que almeja atuar no ambiente global de negócios. Esse foi um ganho para mim. (brasileiro, 21 anos, graduando em Cingapura)

\section{DISCUSSÃO}

\section{SOBRE OS DESAFIOS E OS ELEMENTOS FACILITADORES}

Estudos sobre adaptação intercultural têm reportado que os alunos internacionais vivem um processo de transição e enfrentam diferentes desafios (Hotta; Ting-Toomey, 2013; Dunne, 2013; Lima; Riegel, 2013; Smith; Khawaja, 2011; Brisset, et al., 2010; Mclachlan; Justice, 2009; Jackson, 2008; Chirkov et al., 2008; Ujitani; Volet, 2008). A experiência de mobilidade internacional tem se revelado como um evento transacional acompanhado de estresse em razão do confronto e da necessária adaptação a experiências psicológicas e físicas desconhecidas (Smith; Khawaja, 2011; Brisset, et al., 2010). Os resultados alcançados no presente estudo confirmam tal assertiva e revelam os principais desafios vivenciados por alunos e professores brasileiros no exterior e alunos estrangeiros no Brasil, que perpassam por questões práticas, acadêmicas, sociais e culturais.

Desafios advindos de questões práticas (documentação, acomodação, entre outros) foram relatados por professores e alunos, e ocorrem especialmente no início da experiência. Diferentes pesquisas (Smith; Khawaja, 2011; Berry, 2006; Safdar et al., 2003) apontam tais desafios como potenciais eventos estressores no processo de aculturação de alunos internacionais. Em estudo nacional, Lima e Riegel (2013) também identificaram dificuldades com acomodação e documentação como desafios enfrentados por alunos brasileiros no exterior.

O idioma foi identificado como um dos principais desafios na experiência de mobilidade internacional, o que está em consonância com outros estudos da área (Smith; Khawaja, 2011; Mclachlan; Justice, 2009; Trice, 2003). A importância 
desse desafio foi evidenciada como obstáculo dentro e fora da universidade, gerando principalmente dificuldades acadêmicas. Impactos da barreira linguística nos domínios acadêmico e sociocultural têm sido identificados, sendo que o primeiro foi associado à dificuldade na elaboração da escrita, no entendimento das aulas e na possibilidade de participar oralmente de forma mais efetiva das aulas (Smith; Khawaja, 2011; Olivas; Chi-Sing, 2006; Trice, 2003), desafios relatados pelos alunos e professores brasileiros, assim como pelos alunos estrangeiros entrevistados. No domínio social, a barreira do idioma tem sido associada à dificuldade de fazer amizade e interagir com os nativos (Smith; Khawaja, 2011), aspectos também evidenciados pelos alunos e professores brasileiros no exterior. Por outro lado, o controle do idioma foi apontado por eles como um importante elemento facilitador da experiência da mobilidade, trazendo impactos positivos para adaptação na universidade e fora dela. Esse dado está em consonância com os achados de Poyrazli et al. (2002) e Zhang e Goodson (2011), cujos estudos revelam que a competência na língua estrangeira de alunos internacionais é preditora de boa adaptação sociocultural.

Embora presentes na vida dos universitários em geral, os desafios acadêmicos podem ser intensificados na experiência de mobilidade internacional em razão da necessidade de adaptação a um contexto educacional diferente, com métodos de ensino e de avaliação diferentes de suas universidades de origem (Gu, 2009; Mclachlan; Justice, 2009), o que foi de fato apontado pelos alunos brasileiros e estrangeiros entrevistados. Alguns alunos brasileiros destacam ainda o desafio de se adaptar a uma relação professor-aluno mais distante do ponto de vista afetivo, o que é bastante diferente do tipo de relação desenvolvida com professores no Brasil.

O desejo e a necessidade de formar uma rede social de apoio e fazer novas amizades durante a experiência de mobilidade internacional fazem com que muitos intercambistas enfrentem desafios sociais. Em nosso estudo, tais desafios foram enfatizados pelos alunos brasileiros no exterior, o que eles percebem como falta de abertura por parte dos estudantes locais para formação de amizade e relacionamentos. Os relatos de dificuldades de socialização de alunos intercambistas com locais têm sido recorrentes na literatura (Mclachlan; Justice, 2009; Brown, 2009; Townsend; Poh, 2008; Sawir et al., 2008; Zhang; Brunton, 2007), as quais têm sido usualmente associadas às barreiras do idioma e às diferenças nas normas culturais e na natureza das relações nos países anfitriões. As dificuldades de socialização com alunos locais têm sido associadas ao isolamento e à solidão, especialmente nos meses iniciais da mobilidade (Sawir et al., 2008), o que também pudemos identificar em um caso relatado em nosso estudo. Por outro lado, os alunos estrangeiros no Brasil não relataram dificuldades de relacionamentos sociais dentro ou fora do contexto universitário, mas ao contrário, afirmam que as características do povo brasileiro favorecem a interação social, em razão de sua sociabilidade, sua abertura e seu interesse pelo estrangeiro. Tais dados estão em consonância com outros estudos nacionais (Andrade; Teixeira, 2009; Subuhana, 2009). Andrade e Teixeira (2009) identificaram um grau geral de satisfação de médio a elevado quanto à atenção recebida 
na interação com outras pessoas no Brasil, assim como quanto às amizades que desenvolveram. Da mesma forma, Subuhana (2009), ao analisar a experiência sociocultural de universitários africanos no Brasil, aponta a integração e amizade com os brasileiros como fatores positivos.

Se, por um lado, estabelecer relações com alunos locais é um desafio, por outro, as afinidades construídas com outros intercambistas foram enfatizadas como importantes elementos. Tais resultados evidenciam que alunos em mobilidade tendem a formar redes de relacionamentos com pessoas que compartilham experiências semelhantes, por se constituir uma fonte de apoio e segurança (Lillyman; Bennet, 2014; Zhang; Brunton, 2007; Berry, 2006; Safdar et al., 2003). A tecnologia foi apontada pelos entrevistados como uma facilidade que ameniza a saudade e "encurta" a distância da família e dos amigos, sendo, portanto, importante fonte de apoio social, como identificado nos estudos de Rui e Wang (2015) e Hendrickson et al. (2011). Apoio e acesso ao professor também surgem nos relatos dos participantes entrevistados, corroborando estudos de Ward et al. (2003).

$\mathrm{O}$ apoio da universidade como elemento facilitador da experiência intercultural foi apontado por vários alunos brasileiros. Muitas universidades têm buscado desenvolver serviços de ajuda à adaptação do estudante internacional. Tais medidas têm sido predominantemente voltadas para o auxílio em questões práticas e acadêmicas (Andrade, 2006; Arkoudis, 2006), as quais foram apontadas em nossas entrevistas, como a central de informações, o apoio à busca de moradia, o professor tutor, assim como a organização de eventos de recepção e de integração. A importância e utilidade desse tipo de auxílio ficaram evidenciadas, em concordância com outros estudos (Schweisfurth, 2012; Stronkhorst, 2005; Ward et al., 2003; Jackon, 20015; Berry, 2006; Safdar et al., 2003), e também na fala de alunos brasileiros e estrangeiros que não encontraram essa estrutura por parte da universidade, e enfatizaram o quanto teria sido importante uma atuação mais ativa por parte da instituição.

Um aspecto que ressalta ainda mais a importância de ações de preparo e apoio voltadas aos programas de mobilidade é o preconceito dentro do contexto acadêmico, explicitado por vários alunos e professores brasileiros entrevistados. $\mathrm{O}$ preconceito tem sido indicado na literatura como uma fonte potencial de estresse para alunos internacionais (Lee; Rice, 2007; Poyrazli; Lopes, 2007), pois esta experiência os coloca em posição de vulnerabilidade na sociedade anfitriã (Marginson, 2011). Pelos relatos, percebe-se que o preconceito provoca um grande impacto negativo no processo de adaptação dos alunos, sendo um importante e difícil desafio a ser vencido.

Por fim, temos o retorno ao país de origem, especialmente apontado por alunos brasileiros. O retorno foi percebido como um processo permeado por angústias, preocupações e aflições, como se observa na literatura (Kostohryz, et al., 2014; Szkudlarek, 2010; Brown, 2009), o que afeta o bem-estar psicológico, o ajustamento social e a identidade cultural de indivíduos na volta dos processos de mobilidade. Tais evidências indicam que essa transição merece uma maior atenção. 


\section{SOBRE OS GANHOS ALCANÇADOS E A CONSTRUÇÃO DE UM NOVO CAPITAL SIMBÓLICO}

A experiência de mobilidade internacional, que promove o desenvolvimento de diferentes competências, revela-se um importante capital simbólico para docentes e discentes (Freitas, 2005; 2009; Allemand, 2004; Murphy-Lejeune, 2007, 2003, 2002), ou seja, um diferencial na vida pessoal e profissional dos participantes.

Segundo Freitas (2005), a mobilidade como capital simbólico é compreendida como uma disposição interior, um aprendizado e exercício de abertura às mudanças constantes e compreende a capacidade, a disposição e o desejo do indivíduo de mudar, de interagir com diferenças em relação à cultura, à profissão e aos seus saberes. $\mathrm{O}$ detentor desse capital mostra-se aberto a experiências novas, ao alargamento dos limites de seu conhecimento, de suas experiências pessoais e profissionais e de suas certezas culturais. Trata-se, portanto, de um conjunto de disposições e competências que proporciona abertura para a interação com o outro e com o diferente, e permite o exercício da alteridade na vida pessoal e profissional (Freitas, 2009). Na construção desse capital no contexto universitário, enfatiza-se a riqueza acumulada ao longo da experiência, também facilitada pela bagagem do aluno, pela história familiar e pessoal, pelas competências linguísticas, pelas experiências de viagens anteriores e pelos traços de personalidade (Murphy-Lejeune, 2002).

A análise das entrevistas realizadas nos permite afirmar que a construção desse capital foi se consolidando à medida que alunos e professores enfrentaram diferentes desafios ao longo da experiência de mobilidade, o que converge com as ideias de Murphy-Lejeune (2007). Para a autora, antes da experiência de mobilidade, o estudante pode apresentar competências que serão transformadas durante a experiência em si, sendo o capital de mobilidade modificado e fortalecido à medida que o indivíduo desenvolve estratégias para se adaptar e no processo adquire uma diversidade de habilidades e conhecimentos.

Identificamos em nossa pesquisa que competências pessoais, interculturais, acadêmicas e profissionais podem ser desenvolvidas ao longo da experiência, em consonância com as ideias de Murphy-Lejeune (2007; 2003). Sobre bagagem acumulada, a autora destaca quatro áreas de desenvolvimento do estudante: cognitiva, estratégica, social e pessoal. Embora com nomenclaturas diferentes, constatamos que tais áreas são convergentes com as competências que identificamos.

O desenvolvimento de competências pessoais foi o mais enfatizado pelos alunos brasileiros e estrangeiros, que indicam que a mobilidade proporcionou amadurecimento, autoconhecimento e autonomia, o que vai ao encontro dos achados de outros pesquisadores (Vázquez et al., 2014; Lima; Viegel, 2013; Schweisfurth, 2012; Campbell, 2010; Lima et al., 2009; Brown, 2009; Murphy-Lejeune, 2003).

As competências interculturais são destacadas por alunos brasileiros e estrangeiros, que testemunham que a experiência de mobilidade lhes possibilitou novos conhecimentos, habilidades, atitudes e sensibilidade interculturais. Competências interculturais são habilidades específicas que permitem às pessoas lidarem, de forma eficiente, com situações cuja multiplicidade de referências culturais se faça presente, as quais podem trazer diferentes desafios e tensões, tais como 
discriminação, mudanças culturais e tensões etnográficas relacionadas à comunicação verbal ou não verbal (Manço, 2002). Revelam, portanto, a capacidade do indivíduo de negociar significações culturais e de agir de forma eficaz, reconhecendo as diferentes identidades em um meio (Ogay, 2000). Pesquisas apontam a relevância da competência intercultural na atualidade para o enfretamento dos desafios da diversidade cultural e da globalização, em que cada vez mais profissionais e estudantes vão trabalhar ou estudar em culturas diferentes das suas ou interagem em seu próprio país com pessoas de culturas diversificadas (Leung, et al., 2014; Zee; Oudenhoven, 2013; Vázquez, et al., 2014; Lilyman; Bennett, 2014; Schweisfurth, 2012; Lima; Viegel, 2013; Lumkes Jr., et al., 2010; Lima et al., 2009; Murphy-Lejeune, 2007; Stronkhorst, 2005).

$\mathrm{O}$ aprendizado da língua estrangeira foi apontado como um ganho muito significativo pelos alunos brasileiros e atende uma das grandes expectativas, uma vez que a aprendizagem de um novo idioma foi identificada como fator motivador por vários estudiosos brasileiros (Lima; Riegel, 2013; Ramos, 2009; Lima et al., 2009; Nogueira et al., 2008). Entretanto, o desenvolvimento da competência intercultural proporcionada pela experiência da mobilidade vai além da dimensão linguística, evidenciada nas falas de entrevistados, incluindo o desenvolvimento da sensibilidade e as atitudes interculturais, as quais proporcionam maior flexibilidade na interação com as pessoas, o respeito ao diferente e uma visão mais ampliada e complexa do mundo. Esse conjunto de ganhos reforça a compreensão desse importante capital simbólico, que se expressa em alargamento identitário e crescimento pessoal e intelectual (Murphy-Lejeune, 2002,2007) transferíveis a outros contextos, além do universitário: o profissional, o familiar e o comunitário.

O desenvolvimento de competências acadêmicas foi o menos enfatizado por alunos brasileiros e estrangeiros. Há, na verdade, uma visão clara por parte de alguns alunos de que os ganhos pessoais, interculturais e profissionais são bastante superiores aos acadêmicos. Resultados semelhantes foram encontrados por outros pesquisadores (Vázquez, et al., 2014; Lima; Riegel, 2013; Lumkes Jr. et al., 2012), os quais também identificaram maior ênfase na aquisição de competências pessoais e interculturais do que acadêmicas.

Diferentemente dos alunos brasileiros e estrangeiros, para os professores entrevistados, o desenvolvimento de competências acadêmicas é apontado como o maior ganho da experiência da mobilidade, as quais estão estreitamente relacionadas às competências profissionais, justamente por atuarem na área de docência e pesquisa. A ampliação da compreensão de sua área de estudo, o enriquecimento na forma de desenvolver pesquisas, a elevação do capital cultural, o aumento de credibilidade dos pares, a possibilidade de intercâmbio de conhecimento e de formação de parcerias foram os ganhos apontados, os quais impactaram positivamente em suas competências acadêmicas e profissionais. A ampliação do seu capital social, que possibilita a formação de parcerias acadêmicas e intercâmbio de conhecimento, é um aspecto que tem grande importância não apenas para o crescimento profissional do professor, mas também no processo de internacionalização da instituição no qual atua, uma vez que poderá influenciar de forma 
direta e indireta nesse processo. Muitos acordos acadêmicos institucionais são efetivados a partir da rede de relacionamento construída pelos docentes, além de melhorias em métodos de ensino e pesquisa (Duarte et al., 2012; Sanderson, 2008). É compreensível que um público mais maduro, com bagagem mais complexa e maior objetividade na busca de experiências internacionais privilegie o aspecto profissional e social mais do que os jovens, que ainda estão conhecendo melhor o mundo e a si mesmos.

\section{CONSIDERAÇÕES FINAIS}

A análise e discussão do material obtido acerca das relações interculturais construídas na vida universitária a partir de experiências de mobilidade internacional de docentes e discentes nos permite concluir que um importante capital simbólico pode ser desenvolvido à medida que há o confronto com diferentes desafios e estratégias são lançadas para o enfrentamento e a adaptação. Esse capital caracteriza-se pelo enriquecimento cultural, intelectual e pessoal do indivíduo, que se vê transformado no seu senso de identidade e nos seus valores e suas atitudes socioculturais. Constatamos que as interações e os aprendizados proporcionados pela experiência de mobilidade possibilitam ao indivíduo negociar significados e se construir como pessoa.

Fica evidenciado que a experiência de mobilidade demanda um processo de adaptação, envolvendo a necessidade de superação de tensões emocionais, socioculturais e acadêmicas, e, por isso, faz-se primordial a identificação e potencialização dos fatores facilitadores. A análise desses elementos permite destacar o papel central da universidade nesse processo, atuando como apoiadora para o desenvolvimento bem-sucedido do capital de mobilidade dos atores envolvidos.

Acreditamos que o apoio institucional pode contribuir para aumentar os ganhos da experiência em todos os sentidos, não apenas os pessoais, interculturais e profissionais, mas também os ganhos acadêmicos, tão pouco enfatizados pelos alunos entrevistados.

A análise dos desafios vivenciados na experiência de mobilidade nos permitiu constatar que esse apoio institucional deve se iniciar anteriormente à viagem, no sentido de preparar o aluno para viver a experiência, e precisa se fazer presente ao longo de todo o processo, estendendo-se inclusive para as questões ligadas ao retorno ao país de origem. Cabe também destacar que acreditamos que tanto a instituição de origem como a instituição acolhedora têm um papel central nesse processo, sendo que o auxílio em questões práticas e acadêmicas, assim como ações mais individuais, como de orientação e aconselhamento, são relevantes e necessários.

Tendo em vista minimizar os desafios identificados, intensificar os facilitadores e aumentar os ganhos que podem ser alcançados, refletimos sobre algumas direções de ações possíveis:

- para a universidade de origem: processo de orientação e apoio ao aluno para a elaboração de um plano de estudo no exterior, possibilitando a escolha de disciplinas e atividades que complementem e enriqueçam sua formação e permitam maximizar os ganhos acadêmicos da experiência; 
indicação de um professor-tutor que possa atuar como um elo para o aluno entre sua universidade de origem e a de destino; processo de orientação e apoio no retorno do aluno, tanto com relação às ações práticas a serem tomadas (exemplo: aproveitamento de créditos) como aos desafios psicológicos e sociais (exemplo: inserção em um novo grupo); e

- para a universidade de destino: ter clareza e difundir o papel da instituição, do departamento e dos professores como facilitadores do desenvolvimento de uma identidade intercultural na universidade; facilitar o desenvolvimento de uma mentalidade intercultural, por meio de atividades em grupo que estimulem a integração entre alunos locais e alunos internacionais (exemplo: criação de espaços de convivência, com possibilidades de agendas temáticas de discussão sobre temas variados e atividades culturais diversificadas; seminários e workshops sobre questões culturais do país); preparar professores tutores para que possam proporcionar contínuo apoio e orientação aos alunos internacionais; e manter um canal de comunicação aberto e de fácil acesso entre os alunos internacionais e a instituição.

Entendemos que, embora muitas dessas ações sejam prioritariamente voltadas à realidade do aluno em mobilidade, também o docente que realiza mobilidade para fins de doutorado e pós-doutorado, muito poderá se beneficiar de uma maior sensibilidade intercultural presente no ambiente acadêmico.

A experiência intercultural, quando bem-sucedida, é relatada como um processo transformador de aprendizagem, o qual possibilita uma jornada de crescimento e desenvolvimento. Assim, esperamos que os resultados alcançados nesta pesquisa possam contribuir para o aprimoramento das questões ligadas à interculturalidade no contexto universitário e evidenciem a necessidade de novos estudos na área, que possam investigar importantes implicações da mobilidade para o indivíduo que a realiza, seus pares, a instituição de Ensino Superior e os profissionais que atuam nessa área.

\section{REFERÊNCIAS}

Abdallah-Pretceille, Martine. L'éducation interculturelle. 2. ed. Paris: Presses Universitires de France, 2004.

Allemand, Sylvain. La mobilité comme "capital". Voyages, migrations, mobilités. Sciences Humaines, n. 145, jan. 2004.

Ацтвасн, Philip G. Globalization and the University: myths and realities in an unequal world. The NEA 2005 Almanac of Higher Education, v. 10, n. 1, p. 63-74, 2004. Disponível em: <http://www.tandfonline.com/doi/citedby/10.1080/13583883.2004.9967114?scr oll=top\&needAccess=true> Acesso em: 28 nov. 2014.

Andrade, Maureen Snow. International Students in English-speaking universities. Journal of Research in International Education, v. 5, n. 2, p. 131-154, Aug. 2016. 
Andrade, Ana Maria Jung; Teixeira, Marco Antônio Pereira. Adaptação à universidade de estudantes internacionais: um estudo com alunos de um programa de convênio. Revista Brasileira de Orientação Profissional, v. 10, n. 1, p. 33-44, 2009.

Araújo, Emília Rodrigues; Silva, Sílvia. Temos de fazer um cavalo de Troia: elementos para compreender a internacionalização da investigação e do ensino superior. Revista Brasileira de Educação, v. 20, n. 60, p. 77-98, jan.-mar. 2015.

Arкoudis, Sophie. Teaching International Students: strategies to enhance learning. Centre for the Study of Higher Education, Victoria: University of Melbourne, 2006. BAr Ka, Tania Ogay. De la compétence à la dynamique interculturelles. Tranversales, v. 1, 2000.

Bardin, Laurence. Análise de conteúdo. Portugal: Edições 70, 1995.

Berry, John W. stress perspectives on acculturation. In: SAM, David L.; Berry, John W. (Eds.). The Cambridge Handbook of acculturation psychology. Cambridge: Cambridge University Press, 2006, p. 43-57.

Bourdieu, Pierre. A produção da crença: contribuição para uma economia dos bens simbólicos. 3. ed. Porto Alegre: Zouk, 2006.

. Poder simbólico. 6. ed. Rio de Janeiro: Bertrand, 2003.

. A economia das trocas simbólicas. 2. ed. São Paulo: Perspectiva, 1982.

Brisset, Camile; Safdar, Saba; Lewis, J. Ress; Sabatier, Collete. Psychological and sociocultural adaptation of university students in France: The case of Vietnamese international students. International Journal of Intercultural Relations, v. 34, n. 4, p. 413-426, 2010.

Brown, Lorraine. The transformative power of the International Sojourn: an ethnographic study of the international student experience. Annals of Tourism Research, v. 36, n. 3, p. 502-521, 2009.

CAmpbell, Anne. Developing generic skills and attributes of international students: the (ir)relevance of the Australian university experience. Journal of Higher Education Policy and Management, v. 32, n. 5, p. 487-497, 2010.

Castro, Alda Araújo; Cabral Neto, António. O ensino superior: a mobilidade estudantil como estratégia de internacionalização na América Latina. Revista Lusófona de Educação, v. 21, n. 21, p. 69-96, 2012.

Ciência Sem Fronteiras. O programa. Disponível em: <http://www. cienciasemfronteiras.gov.br> Acesso em: 7 mar. 2016.

Chirkov, Valery I.; Safdar, Saba; Guzman, J.; Playford, K. Further examining the role motivation to study abroad plays in the adaptation of international students in Canada. International Journal of Intercultural Relations, v. 32, n. 5, p. 427-440, 2008.

De Carlo, Maddalena. L'interculturel. Didactique des langues étrangères. Paris: CLE International, 1998.

De Wiт, Hans. Recet trends and issues in international student mobility. International Higher Education, n. 59, p. 13-14, 2010. 
Duarte, Roberto Gonzalez; Castro, José Márcio; Cruz, Ana Luiza Albuquerque; MiURA, Irene K. et al. O papel dos relacionamentos interpessoais na internacionalização de instituições de ensino superior. Educação em Revista, v. 28, n. 1, p. 343-370, mar. 2012.

Dunne, Ciarán. Exploring motivations for intercultural contact among host country university students: An Irish case study. International Journal of Intercultural Relations, v. 37, n. 5, p. 567-578, 2013.

Freitas, Maria Ester. A mobilidade como novo capital simbólico nas organizações ou sejamos nômades? In: BARBosA, Livia. (Coord.). Cultura e diferença nas organizaçöes. Reflexões sobre nós e os outros. São Paulo: Atlas, 2009. p. 89-115.

. O imperativo intercultural na vida e na gestão contemporânea. Organizações E Sociedade, v. 15, n. 45, p. 79-89, abr.-jun. 2008.

. Executivos brasileiros expatriados na França. Monografia para concurso de professor titular. São Paulo: EAESP/FGV, 2005.

Gu, Qing. Maturity and Interculturality: Chinese students' experiences in UK higher education. European Journal of Education, v. 44, n. 1, p. 37-52, 2009.

Guimarães, Sandra Ritiele Espíndola Fernandes; Tadeucci, Marilsa de Sá; Oliveira, Adriana Leonidas. Estudo Bibliométrico em gestão intercultural, internacionalização e mobilidade acadêmica: foco no ensino superior.Janus, n. 17, p. 55-65, 2013.

Hendrickson, Blake; Rosen, Devan; Aune, R. Kelly. An analysis of friendship networks, social connectedness, homesickness, and satisfaction levels of international students. International Journal of Intercultural Relations, v. 35, n. 5, p. 281-295, 2011.

Hotta; Jean; Ting-Toomey, Stella. Intercultural adjustment and friendship dialectics in international students: A qualitative study. International Journal of Intercultural Relations, n. 37, p. 550-566, 2013.

JACKsON, Jane. Becoming interculturally competent: Theory to practice in international education. International Journal of Intercultural Relations, v. 48, p. 91-107, 2015.

. Globalization, internationalization, and short-term stays abroad. International Journal of Intercultural Relations, n. 32, p. 349-358, 2008.

Knight, Jane. Understanding Education Hubs within the Context of Crossborder Education.In: (Ed.). International Education Hubs: student, talent, knowledgeinnovation models. New York: Springer, 2014. p. 13-27.

. Modèle d' internationalisation ou comment faire face aux réalités et enjeux nouveaux. In: OCDE. L'enseignement supérieur en Amérique Latine: la dimension internationale. Paris: OCDE, 2005. p. 11-45.

Kostohryz, Katie; Wells, Pamela; Walthen, Cristen; Wilson, David. More than a vacation: exploring the impact of reentry for international sojourners. Journal of Mental Health Counseling, v. 36, n. 4, p. 315-328, Oct. 2014.

Lauermann, Fani. To go or not to go: the decision to pursue higher education abroad. Advances in Motivation and Achievement, v. 17, p. 177-204, 2012. 
LeE, Jenny J.; Rice, Charles. Welcome to America? International students perceptions of discrimination. Higher Education: The International Journal of Higher Education and Educational Planning, v. 53, n. 3, p. 381-409, 2007.

Leung, Kwok; Ang, Soon; Tan, Mei Ling. Intercultural competence. Annual Review of Organizational Psychology and Organizational Behavior, v. 1, p. 489-519, 2014.

Lillyman, Sue ; Bennett, Clare. Providing a positive learning experience for international students studying at UK universities: a literature review. Journal of Research in International Education, v. 13, n. 1, p. 63-75, 2014.

Lima, Manolita Correia; Riegel, Viviane. A influência da mobilidade acadêmica sobre a formação dos jovens. Negócios e Talento, v. 2, n. 11, 2013.

Lima, Manolita Correia; Contel, Fabio Betioli. Internacionalização da educação superior. Nações ativas, nações passivas e a geopolítica do conhecimento. São Paulo: Alameda, 2011.

Lıma, Manolita Correia, et al. Motivações da mobilidade acadêmica entre estudantes do curso de administração. In: ENEPQ 2, 2009, Curitiba. Anais... Curitiba: ANPAD, 2009.

Lima, Manolita Correia; Maranhão, Carolina Machado Saraiva de Albuquerque. O sistema de educação superior mundial: entre a internacionalização ativa e passiva. Avaliação, v. 14, n. 3, p. 583-610, nov. 2009.

Lumkes, Jr., John H.; Hallett, Steven; Vallade, Linda. Hearing versus experiencing: the impact of a short-term study abrad experience in China on students perceptions regarding globalization and cultural awareness. International Journal of Intercultural Relations, v. 36, n. 1, p. 151-159, 2012.

Manço, Altay. Compétences interculturelles des jeunes issus de l'immigration: perspectives théoriques et pratiques. Paris: Harmattan, 2002.

Marginson, simon. Including the other: regulation of the human rights of mobile students in a nation-bound world. High Education, n. 63, p. 497-512, 2011.

Mclachlan, Debra A.; Justice, Jessica. A grounded theory of international student well-being. Journal of Theory Construction E Testing, v. 13, n. 1, p. 27-32, 2009.

Morosini, Marília Costa. Estado do conhecimento sobre internacionalização da educação superior - Conceitos e práticas. Educar, Curitiba, n. 28, p. 107-124, 2006.

Murphy-Lejeune, e. Identity, culture and language learning: the benefits of a mobility capital. In: Pearson-Evans, Aileen; Leahy, Angela (Ed.). Intercultural spaces: language, culture, identity. New York: Peter Lang Publishing, 2007. cap. 18.

. An experience of interculturality: student travellers abroad. In: Alred, Geof; Byram, Michael; Fleming, Mike (Ed.). Intercultural experience and education. Great Britain: Cromwell Press, 2003. cap. 7, p. 101-113.

. Student mobility and narrative in Europe: the new strangers. London: Routledge, 2002.

Nogueira, Maria Alice; Aguiar, Andrea Moura de Souza; Ramos, Viviane Coelho Caldeira. Fronteiras desafiadas: a internacionalização das experiências escolares. Educação e Sociedade, v. 29, n. 103, p. 355-376, ago. 2008. 
Organização para a Cooperação e Desenvolvimento Econômico (OCDE). Education at A Glance 2012. Paris: OCDE, 2012.

Olivas, Monique; LI, Chi-Sing. Understanding Stressors of International Students in Higher Education: What College Counselors and Personnel Need to Know. Journal of Instructional Psychology, v. 33, n. 3, p. 217-222, Sep. 2006.

Oliveira, A. L. Comportamento organizacional e pesquisa qualitativa. In: Chamon, Edna Maria Querido de Oliveira (Org.). Gestão e comportamento humano nas organizações. Rio de Janeiro: Brasport, 2007, p. 180-205.

Poyrazli, Senel; Arbona, Consuelo; Nora, Amaury; McPherson, Robert; Stewart Pisecco. Relation between Assertiveness, Academic Self-Efficacy, and Psychosocial Adjustment among International Graduate Students. Journal of College Student Development, v. 43, n. 5, p. 632-42, Sep.-Oct. 2002.

Poyrazli, Senel; Lopez, M. D. An exploratory study of perceived discrimination and homesickness: a comparison of international students and American Students. The Journal of Psychology, v. 141, n. 3, p. 263-280, 2007.

Ramos, Viviane Coelho Caldeira. Perfil e motivaçôes dos estudantes participantes do "Programa de mobilidade discente internacional para a graduaşão" da UFMG. 2009. $137 \mathrm{f}$. Dissertação (Mestrado em Educação) - Faculdade de Educação da Universidade Federal de Minas Gerais, MG, 2009.

RuI, Jian Raymond; WANG, Hua. Social network sites and international students' crosscultural adaptation. Computers in Human Behavior, v. 49, p. 400-411, 2015.

Safdar, Saba; Lay, Clarry; Struthers, Ward. The process of acculturation and basic goals: testing a multidimensional individual difference acculturation model with iranian immigrants in Canada. Applied Psychology, v. 52, n. 4, p. 555-579, 2003.

Sanderson, Gavin. A foundation for the internationalization of the academic self. Journal of Studies in International Education, v. 12. n. 3, p. 276-307, 2008.

Sawir, Erlenawati; Marginson, Simon; Deumert, Ana; Ramia, Gaby. Loneliness and international students: an australian study. Journal of Studies in International Education, v. 20, n. 10, p. 1-33, 2008.

Schweisfurth, Michele. Are Sojourners natural comparativists? Critical perspectives on learning experiences of international students. Research in Comparative and International Education, v. 7, n. 1, p. 81-89, 2012.

Seidel, John. Ethnograph v5.0: a user's guide. California: Sage Publications, 1998.

SeIdel, John; Clark, Jack A. The ethnograph: a computer program for the analysis of qualitative data. Qualitative Sociology, v. 7, n. 1-2, p. 110-125, 1984.

Sмiтн; Rachel A.; Khawaja, Nigar G. A review of the acculturaion experiences of international students. International Journal of Intercultural Relations, n. 35, p. 699-713, 2011.

Stallivieri, Luciane. Estratégias de internacionalização das universidades brasileiras. Caxias do Sul: EDUCS, 2004. 
Stronkhorst, Robert. Learning outcomes of international mobility at two dutch institutions of higher education. Journal of Studies in International Education, v. 9, n. 4, p. 292-315, 2005.

Subuhana, Carlos. A experiência sociocultural de universitários da África Lusófona no Brasil: entremeando histórias. Pro-Posiçōes, v. 20, n. 1, p. 103-126, 2009.

Szkudlarek, Betina. Reentry - A review of the literature. International Journal of Intercultural Relations, v. 34, n. 1, p.1-21, 2010.

Townsend, Peter; Poh, Huay Jun. An exploratory study of international students studying and living in a regional area. Journal of Marketing for Higher Education, n. 18, p. 240-263, 2008.

Trice, Andrea G. Faculty perceptions of graduate international students: The benefits and challenges. Journal of Studies in International Education, v. 7, n. 4, p. 379-403, Dec. 2003.

Ujitani, Eiko; Volet, Simone. Socio-emotional challenges in International Education. Journal of Research in International Education, v. 7, n. 3, p. 279-303, 2008.

Unesco. Conferencia Mundial sobre la Educación Superior-2009: la nueva dinâmica de la educación superior e la investigación para el cambio social y el desarrollo: comunicado. Paris, 2009. Disponível em: <www.unesco.org/education/WCHE2009/comunicado_ es.pdf.> Acesso em: 29 nov. 2014.

. Conferência Mundial sobre o Ensino Superior: tendências de educação superior para o século XXI. Paris, 1998. Disponível em: <www.unesco.org/education/educprogr/ wche.htm/>. Acesso em: 12 dez. 2014.

Urban, Ewa L.; Palmer, Louann Bierlein. International Students as a resource for internationalization of Higher Education. Journal of Studies in International Education, v. 18, n. 4, p. 305-324, 2014.

VÁzquez, Lynda K.; Mesa, Francisco R.; López, Daniel A. To the ends of the Earth: student mobility in Southern Chile. International Journal of Educational Management, v. 28, n. 1, p. 82-95, 2014.

WARD et al. The Psychology of culture shock. 2. ed. USA: Routledge, 2003.

Wende, M. C. van der. Global Institutions: the Organisation for Economic Cooperation and development. In: KING, Roger; MARGINson, simon; NAIDOo, rajani (Eds). Handbook on Globalization and Higher Education. USA: Edward Elgar, 2011, p. 95-114. Van der Zee, Karen; Oudenhoven, Jan Pieter van. Culture shock or challenge? The role of personality as a determinant of intercultural competence. Journal of Cross-Cultural Psychology, v. 44, n. 6, p. 928-940, 2013.

Zhang, Jing; Goodson, Patricia. Predictors of international students' psychosocial adjustment to life in the United States: a systematic review. International Journal of Intercultural Relations, v. 35, n. 2, p. 139-162, 2011.

Zhang, Zhiheng; Brunton, Margaret. Differences in living and learning: Chinese international students in New Zealand. Journal of Studies in International Education, v. 11, n. 2, p. 124-140, Jun. 2007. 


\section{SOBRE AS AUTORAS}

Adriana Leônidas de Oliveira é doutora em psicologia pela Pontifícia Universidade Católica de São Paulo (PUC-SP). Professora da Universidade de Taubaté (UNITAU).

E-mail: adrianaleonidas@uol.com.br

Maria Ester de Freitas é doutora em administração de empresas pela Fundação Getulio Vargas (FGV-EAESP). Professora da mesma instituição.

E-mail: ester.freitas@fgv.br

Recebido em 25 de outubro de 2015 Aprovado em 4 de abril de 2016 